\title{
Comparative Effects of Inulin with Different Polymerization Degrees on Growth Performance, Blood Trace Minerals, and Erythrocyte Indices in Growing-Finishing Pigs
}

\author{
W. Samolińska ${ }^{1}$ (D) E. R. Grela ${ }^{1}$ \\ Received: 3 April 2016 / Accepted: 30 June 2016 / Published online: 19 July 2016 \\ (C) The Author(s) 2016. This article is published with open access at Springerlink.com
}

\begin{abstract}
There are numerous reports of the effect of inulin on the bioavailability of mineral compounds. However, there are no conclusive reports concerning its beneficial impact (or lack thereof) in the case of such essential trace elements as iron, copper, or zinc. The aim of the study was to compare the effects of inulin addition with different degrees of polymerization (DPs) on growth performance in fatteners as well as on blood plasma concentrations of iron, copper, and zinc and selected hematological indices. The experiment was conducted throughout the fattening period (up to a body weight of approximately $115 \mathrm{~kg}$ ) on 112 weaners with an initial weight of $25.0 \pm 0.5 \mathrm{~kg}$ divided into 7 groups. The first group served as a control, while the other groups received increasing doses $(1,2$, and $3 \%)$ of standard inulin (SI; $\left.\mathrm{DP}_{\mathrm{av}} \geq 10\right)$ or long-chain inulin (LCI, DP $\mathrm{av}_{\mathrm{v}} \geq 23$ ) in complete mixtures. Compared with the control, the supplementation of the mixtures with inulin increased the average daily gains, the final body weight, and the plasma content of trace elements $(P<0.05)$. An increased plasma zinc concentration was noted after application of inulin with a lower polymerization degree $(P<0.05)$. In turn, at a higher inulin polymerization degree, a higher final body weight and increased copper $(P<0.05)$, iron $(P<0.1)$, hemoglobin, mean corpuscular hemoglobin concentration (MCHC), and packed cell volume (PCV) levels were detected in animal blood $(P<0.05)$. The inulin addition was found to have modified the analyzed indices, and the optimal supplementation level was estimated at $20 \mathrm{~g} \cdot \mathrm{kg}^{-1}$ diet. Inulin with
\end{abstract}

W. Samolińska

wioletta.samolinska@up.lublin.pl

1 Department of Bromatology and Food Physiology, Institute of Animal Nutrition and Bromatology, University of Life Science, Lublin, Poland the higher DP exerted a more pronounced effect on the analyzed properties.

Keywords Inulin Pigs $\cdot$ Iron $\cdot$ Copper $\cdot$ Zinc $\cdot$ Hematology indices

\section{Introduction}

Inulin is a mixture of oligomers and linear fructose polymers with a varying degree of polymerization (DP) ranging from 2 to ca. 65 units with an average degree of polymerization $\left(\mathrm{DP}_{\mathrm{av}}\right)=12[1,2]$. In the gastrointestinal tract, inulin is a hydrolysis and fermentation substrate for the beneficial intestinal microbiota and increases the abundance of bacteria, primarily from the genus Bifidobacterium [3] and some Lactobacillus species [4,5]. The molecule length is important for the technological and prebiotic properties of inulin [6-8] and depends on the source and extraction processes [9]. For instance, the number of fructose units and the polymerization degree (DP, 2-10; average 5) are reduced in the oligofructose obtained after partial enzymatic hydrolysis of chicory inulin [10]. The differences in the polymerization degree in fructans may affect not only their physicochemical and technological properties but also their biological traits. As shown by the investigations conducted by van de Wiele et al. [6], application of inulin was accompanied by increased production of short-chain fatty acids (SCFAs), greater Bifidobacterium abundance, and a stronger bifidogenic effect than that noted upon application of oligofructose, which is characterized by a lower polymerization degree. Inulin has been shown to be suitable for enhancement of the bioavailability of mineral compounds [11-15]. This is associated with stimulation of SCFA production by microorganisms, which reduce the $\mathrm{pH}$ of the intestinal tract, thereby increasing the solubility of 
minerals. Similarly, enhanced proliferation of intestinal epithelial cells in response to SCFA formation leads to an increase in the area available for mineral absorption. The bioavailability of mineral compounds can also be changed by the expression of nutrient transport proteins or regulatory genes involved in the absorption process [12, 16-19].

Among trace metals, iron, copper, and zinc are regarded as essential for the organism function. They are present in normal tissues at a relatively constant level, and their deficiency causes similar structural and physiological disorders both in various animal species and in humans [20]. Maintenance of homeostasis of these elements in the organism strongly influences erythropoietic processes and, consequently, red blood cell indices [21]. Strong antagonistic or synergistic interactions have been observed between these metals, including competitive inhibition of their bioavailability and transport in the gastrointestinal tract, which can simultaneously be reflected in their blood concentrations [22-26]. Blood serum and plasma are frequently tested for assessment of the normal trace element supply of the organism. The element content in the organism is a result of a dynamic balance between the demand and the amount supplied and the capability of elimination thereof $[27,28]$.

Until now, investigations of the inulin application in the nutrition for various animal species have yielded many ambiguous results concerning its impact (or lack thereof) on the bioavailability of essential trace elements, e.g., iron, copper, and zinc $[13-15,18,19,29-36]$. This may be related to the application of inulin with different degrees of polymerization, which was emphasized in investigations conducted on piglets by Yasuda et al. [37] and Patterson et al. [38]. The available literature provides few reports of the inulin supplementation effects in older pigs' diet [39]. This aspect may be interesting, as the effect of inulin in older animals may differ from that noted in piglets.

Hence, the aim of the study was to evaluate the effects of the inulin polymerization degree and its increasing doses supplemented in mixtures for pigs throughout the fattening period on growth performance as well as plasma iron, copper, and zinc levels and the related erythrocyte indicators.

\section{Material and Methods}

\section{Animals, Diets, and Experimental Design}

The experiment was conducted on 112 crossbreed weaners (Polish Landrace $\times$ Polish Large White $) \times$ Duroc with an initial weight of $25.0 \pm 0.5 \mathrm{~kg}$, divided into 7 equinumerous groups (16 pigs per group). Four animals per pen (two gilts + two barrows) were kept. The animals were fattened for 105 days. Each pen was equipped with a stainless steel selffeeder and a nipple drinker. Pigs had free access to feed and drinking water throughout the experimental period. Fatteners were fed ad libitum with complete diets, i.e., grower (25$70 \mathrm{~kg}$ ) and finisher $(71-115 \mathrm{~kg})$. The hygienic conditions, i.e., the temperature, relative humidity, and cooling were the same for all the groups.

The supplementation with increasing doses of 10, 20, and $30 \mathrm{~g}$ per $1 \mathrm{~kg}$ of the feed mixture of two types of inulin extracted from chicory (Cichorium intybus L.) roots, differing in the DP, i.e., standard inulin (SI group, Orafti ${ }^{\circledR} \mathrm{GR}, \mathrm{DP}_{\mathrm{av}}$ of inulin $\geq 10$ ) or long-chain inulin (LCI group, Orafti® HPX, $\mathrm{DP}_{\mathrm{av}}$ of inulin $\geq 23$ ) was an experimental factor. The control group in the investigations was not supplemented with inulin. Commercial inulin replaced cornstarch in the control diet. The dietary composition and analysis are presented in Table 1.

All pigs used in this study were examined and considered clinically healthy by a veterinarian. The study was approved by the Local Ethics Committee on Animal Experimentation of the University of Life Sciences in Lublin, Poland.

\section{Growth Performance}

During the experiment, the animals were weighed at the start and before slaughter. Feed intake was controlled individually by weighing portions for automatic feed in the pens. The feedto-gain ratio $(\mathrm{F} / \mathrm{G})$ was calculated.

\section{Sample Collection and Chemical Analyses}

The total protein content was determined in the mixtures (AOAC 2000 [40]). The amino acid contents were determined using an automatic amino acid analyzer (AAA 400, Ingos, Czech Republic) after previous acid hydrolysis with $6 \mathrm{M}$ $\mathrm{HCl}$ (method 994.12, AOAC 2000). Sulfur amino acids (cysteine and methionine) were determined in a separate analysis as oxidized derivatives (cystic acid and methionine sulfone) derived through performic acid oxidation and next released from proteins in the process of classic acid hydrolysis [41].

Samples of the mixtures were dried at $100{ }^{\circ} \mathrm{C}$ for $24 \mathrm{~h}$ and ashed for $10 \mathrm{~h}$ at $550^{\circ} \mathrm{C}$. The ashed samples were dissolved in a nitric acid-perchloric acid mixture $(1: 1)$ and diluted with deionized water for mineral analysis. The $\mathrm{Fe}, \mathrm{Zn}, \mathrm{Cu}$, and $\mathrm{Ca}$ contents were measured using flame atomic absorption spectrophotometry (FAAS) (Unicam 939/959AA-6300, Shimadzu Corp., Tokyo, Japan), according to the Polish Standard (PN-EN ISO 6869:2002 [42]), and the total P content was determined colorimetrically (PN-76/R-64781:1976 [43]) with a Helios Alpha UV-Vis apparatus (Spectronic Unicam, Leeds, UK).

Blood samples were taken from the external jugular vein of six clinically healthy animals (three gilts and three barrows) fasted overnight for $8 \mathrm{~h}$, twice from each group, when the body weights were 50 and $100 \mathrm{~kg}$. Blood samples for hematological analyses were collected in 2-ml Vacutest tubes with a 
Table 1 Ingredients and chemical composition of the experimental diets (as fed basis)

\begin{tabular}{|c|c|c|c|c|c|c|c|c|}
\hline \multirow{2}{*}{$\begin{array}{l}\text { Diet type } \\
\text { Inulin supplementation } \\
\text { Feeding phase }\end{array}$} & \multirow{2}{*}{$\begin{array}{l}\text { Control } \\
0 \mathrm{~g} \\
\text { Grower }\end{array}$} & \multicolumn{3}{|c|}{ Standard inulin (SI)/long-chain inulin (LCI) } & \multirow{2}{*}{$\begin{array}{l}\text { Control } \\
0 \mathrm{~g} \\
\text { Finisher }\end{array}$} & \multicolumn{3}{|c|}{ Standard inulin (SI)/long-chain inulin (LCI) } \\
\hline & & $\begin{array}{l}10 \mathrm{~g} \\
25-70 \mathrm{~kg})\end{array}$ & $20 \mathrm{~g}$ & $30 \mathrm{~g}$ & & $\begin{array}{l}10 \mathrm{~g} \\
71-115 \mathrm{~kg})\end{array}$ & $20 \mathrm{~g}$ & $30 \mathrm{~g}$ \\
\hline \multicolumn{9}{|l|}{ Ingredients $(\%)$} \\
\hline Wheat & 30.0 & 30.0 & 30.0 & 30.0 & 25.0 & 25.0 & 25.0 & 25.0 \\
\hline Barley & 37.5 & 37.5 & 37.5 & 37.5 & 53.1 & 53.1 & 53.1 & 53.1 \\
\hline $\begin{array}{l}\text { Soybean meal } \\
(460 \mathrm{~g} / \mathrm{kg} \mathrm{CP})\end{array}$ & 24.2 & 24.2 & 24.2 & 24.2 & 15.0 & 15.0 & 15.0 & 15.0 \\
\hline Soybean oil & 1.2 & 1.2 & 1.2 & 1.2 & 0.5 & 0.5 & 0.5 & 0.5 \\
\hline Corn starch & 3.0 & 2.0 & 1.0 & 0,0 & 3.0 & 2.0 & 1.0 & 0.0 \\
\hline Premix $^{a}$ & 2.0 & 2.0 & 2.0 & 2.0 & 1.5 & 1.5 & 1.5 & 1.5 \\
\hline Inulin & 0.0 & 1.0 & 2.0 & 3.0 & 0.0 & 1.0 & 2.0 & 3.0 \\
\hline Monocalcium phosphate & 0.4 & 0.4 & 0.4 & 0.4 & 0.3 & 0.3 & 0.3 & 0.3 \\
\hline Limestone ground & 1.2 & 1.2 & 1.2 & 1.2 & 1.1 & 1.1 & 1.1 & 1.1 \\
\hline Sodium chloride & 0.3 & 0.3 & 0.3 & 0.3 & 0.3 & 0.3 & 0.3 & 0.3 \\
\hline L-Lysine & 0.2 & 0.2 & 0.2 & 0.2 & 0.2 & 0.2 & 0.2 & 0.2 \\
\hline Total & 100.00 & 100.00 & 100.00 & 100.00 & 100.00 & 100.00 & 100.00 & 100.00 \\
\hline \multicolumn{9}{|l|}{$\begin{array}{l}\text { Chemical composition } \\
\left(\mathrm{g}^{\mathrm{kg}} \mathrm{g}^{-1}\right)\end{array}$} \\
\hline $\mathrm{ME} \mathrm{MJ} / \mathrm{kg}^{\mathrm{b}}$ & 13.14 & 13.14 & 13.13 & 13.13 & 12.91 & 12.90 & 12.88 & 12.87 \\
\hline Crude protein $(\mathrm{g})$ & 171.3 & 171.2 & 171.1 & 171.1 & 158.3 & 158.1 & 158.2 & 158.1 \\
\hline Lysine (g) & 10.8 & 10.7 & 10.7 & 10.6 & 8.83 & 8.83 & 8.83 & 8.82 \\
\hline Methionine + cysteine $(\mathrm{g})$ & 5.82 & 5.81 & 5.79 & 5.79 & 5.43 & 5.43 & 5.42 & 5.42 \\
\hline Total calcium (g) & 7.12 & 7.12 & 7.11 & 7.12 & 6.45 & 6.45 & 6.45 & 6.44 \\
\hline Total phosphorus (g) & 5.07 & 5.07 & 5.06 & 5.06 & 4.87 & 4.87 & 4.87 & 4.87 \\
\hline Total iron (mg) & 106.56 & 105.44 & 106.5 & 105.37 & 98.81 & 98.64 & 98.57 & 98.72 \\
\hline Total zinc (mg) & 107.38 & 106.41 & 106.83 & 106.9 & 99.01 & 98.99 & 99.19 & 98.81 \\
\hline Total copper (mg) & 7.87 & 7.79 & 7.71 & 7.9 & 6.8 & 6.72 & 6.73 & 6.79 \\
\hline
\end{tabular}

SI standard inulin (Oraftiß GR contained $\sim 92 \%$ inulin, $\sim 8 \%$ glucose, fructose, and sucrose (solubility $<12 \mathrm{~g} \mathrm{~L}^{-1}$ and DP $\geq 10$ ) (Beneo-Orafti, Tienen, Belgium), LCI long-chain inulin Oraftiß HPX contained $100 \%$ inulin (solubility $<5 \mathrm{~g} \mathrm{~L}^{-1}$ and degree of polymerization $\left.(D P) \geq 23\right)($ Beneo-Orafti, Tienen, Belgium)

${ }^{a}$ One kilogram of the premix contained vitamin A 500,000 IU; D $90,000 \mathrm{IU}$; E $5000 \mathrm{mg} ; \mathrm{K}_{3} 90 \mathrm{mg}$; $\mathrm{B}_{1} 90 \mathrm{mg}$; $\mathrm{B}_{2} 300 \mathrm{mg}$; $\mathrm{B}_{6} 150 \mathrm{mg}$; $\mathrm{B}_{12} 1.5 \mathrm{mg}$; nicotinic acid $1500 \mathrm{mg}$; pantothenic acid $700 \mathrm{mg}$; folic acid $160 \mathrm{mg}$; biotine $5 \mathrm{mg}$; choline chloride $12 \mathrm{~g} ; \mathrm{Mg} 12.5 \mathrm{~g} ; \mathrm{Fe} 1.5 \mathrm{~g} ; \mathrm{Zn} 4 \mathrm{~g} ; \mathrm{Mn} 3.5 \mathrm{~g}$; Cu $100 \mathrm{mg}$; I $75 \mathrm{mg}$, Se $20 \mathrm{mg}$, Co $25 \mathrm{mg}$

${ }^{\mathrm{b}}$ Calculated according to the NRC [59]

$\mathrm{K}_{3}$ EDTA anticoagulant (Vacutest Kima s.r.l., Arzergrande (PD), Italy). For biochemical assays, blood was sampled in 6-ml Vacutest tubes containing lithium heparin (Vacutest Kima s.r.l., Arzergrande (PD), Italy).

Whole blood was analyzed within 3 hours after sampling. After placement of the samples on the hematological mixer (UMH-5, Wigo, Pruszkow, Poland), the red blood cell (RBC) count and the hemoglobin content (HGB) were determined using a hematological analyzer ABACUS Junior Vet (Automatic cell counter, Diatron, Vienna, Austria). The packed cell volume (PCV) was determined with the microhematocrit method. The analyses performed also included determination of other parameters of the red blood cell system. The mean cell volume (MCV) indicates the volume of an average red cell in a sample expressed in femtoliters ( $\mathrm{fl}$ ) and calculated using the following formula: MCV $(\mathrm{fl})=\mathrm{PCV} \times 1000 / \mathrm{RBC}$. Mean cell hemoglobin $(\mathrm{MCH})$ represents the absolute hemoglobin amount in an average red cell in a sample in units of picograms (pg) per cell. The $\mathrm{MCH}$ is calculated from the hemoglobin and the RBC using the following formula: $\mathrm{MCH}(\mathrm{pg})=\left(\mathrm{HGB}\left(\mathrm{g} \cdot \mathrm{dl}^{-1}\right) \times 10\right) /$ RBC. The mean corpuscular hemoglobin concentration $(\mathrm{MCHC})$ is the average hemoglobin concentration in red blood cells calculated as follows: $\mathrm{MCHC}$ (mmol. $\left.1^{-1}\right)=$ HGB / PCV [44]

Plasma for analysis of the biochemical parameters was obtained by centrifugation of whole blood at $3000 \mathrm{rpm}(603 \times \mathrm{g})$ for $15 \mathrm{~min}$ in a laboratory centrifuge (MPW-350R, MPW 
Medical Instruments, Warsaw, Poland) at a temperature of $4{ }^{\circ} \mathrm{C}$. Plasma without hemolysis signs was analyzed within $4 \mathrm{~h}$ after sampling, and the iron, zinc, and copper contents were determined. The elements were determined in blood plasma with colorimetric methods according to the manufacturer's protocol using reagent kits (BioMaxima, Lublin, Poland; Hydrex Diagnostics, Warsaw, Poland) and a random access biochemical analyzer Metrolab 2300 GL (Metrolab SA, Buenos Aires, Argentine). The intra-assay coefficients of variation (CVs) of the method declared by the manufacturer were $<4.5,2.4$, and $<2.6 \%$ for the iron, zinc, and cooper determinations, respectively. The analysis procedures were verified with the use of multiparametric control plasma (BioCal), as well as control plasma of a normal level (BioNorm) and a high level (BioPath) of elements (BioMaxima, Lublin, Poland; Hydrex Diagnostics, Warsaw, Poland).

\section{Statistical Analysis}

All calculations were performed with statistical software package Statistica 10.0PL (StatSoft Inc. [45]). The normality and homogeneity of variances were tested using the Shapiro-Wilk and the Brown-Forsythe tests, respectively. For comparative purposes, two types of statistical analyses were performed using a general linear model (GLM).

Model 1. The effects of supplemental dietary inulin on the $\mathrm{Cu}, \mathrm{Zn}$, and $\mathrm{Fe}$ plasma concentrations, red blood cell indices, and growth performance traits were analyzed using one-way analysis of variance (ANOVA; using Fisher test or Welch test):

$\mathrm{Y}_{i j}=\mu+\mathrm{a}_{i}+\mathrm{e}_{i j}$

where $Y_{i j}$ is the measured variable, $\mu$ is an overall mean, $a_{i}$ is the dietary inulin effect (treatment), and $\mathrm{e}_{i j}$ is the random error.

Model 2. A two-way ANOVA was performed with the GLM procedure to test the main effects and their interaction. The following model was used:

$\mathrm{Y}_{i j k}=\mu+\mathrm{A}_{i}+\mathrm{B}_{j}+\mathrm{AB}_{i j}+\mathrm{e}_{i j k}$

where $\mathrm{Y}_{i j k}$ is the measured variable, $\mu$ is an overall mean, $\mathrm{A}_{i}$ is the effect of the $i$ th type of the inulin extract, $\mathrm{B} j$ is the effect of the $j$ th level of the inulin supplement, $\mathrm{AB}_{i j}$ is the interaction of $\mathrm{A}_{i}$ and $\mathrm{B}_{j}$, and $\mathrm{e}_{i j k}$ is the random error. Means were compared using Duncan's multiple range test. All statements of significance are based on a probability $<0.05$ and $P$ values between
0.05 and 0.1 were considered as a trend.

In order to check the correlations between the inulin addition to the mixtures and the magnitude of the growth performance, $\mathrm{Cu}, \mathrm{Zn}$, and Fe plasma concentrations, and red blood cell indices, we calculated Pearson correlation coefficients $(r)$ for the increasing inulin levels $\left(10,20\right.$, and $30 \mathrm{~g} \cdot \mathrm{kg}^{-1}$ mixture) and Spearman rank correlation coefficients $(R)$ for the use of inulin with the various degrees of polymerization (groups: SI, $\mathrm{DP}_{\mathrm{av}} \geq 10$ or LCI, $\mathrm{DP}_{\mathrm{av}} \geq 23$ ). The coefficient of determination $\left(r^{2}\right)$ was calculated for evaluation of the correlations between the variables.

\section{Results}

\section{Growth Performance}

The inulin addition to the mixtures did not have an impact on the feed intake in the fatteners or on the feed-to-gain ratio throughout the feeding period (Table 2). In turn, an increase in the average daily weight gain was observed (one-way ANOVA, $P=0.041$ ) as well as a strong tendency toward an increase in the total weight gain throughout the feeding period (one-way ANOVA, $P=0.061$ ), compared with the control group. Inulin supplementation of the mixtures elevated the final body weight of the fatteners (one-way ANOVA, $P=0.035$ ). The multivariate analysis of variance confirmed the significant effect of the degree of inulin polymerization (IDP) on the analyzed growth indices. The addition of the long-chain inulin ( $\left.\mathrm{LCI} ; \mathrm{DP}_{\mathrm{av}} \geq 23\right)$ exerted a more pronounced effect on the average daily weight gain (two-way ANOVA, $P=0.083$ ) and increased the final body weight of the fatteners (two-way ANOVA, $P=0.048$ ). The amount of the additive and the interaction between the two factors appeared to be statistically insignificant. The absence of such an interaction may indicate that the explanatory variables were uncorrelated in this experiment, and the differences in the level of one variable did not alter the other.

A low positive correlation was only found between the degree of inulin polymerization and the final body weight of the fatteners $(R=0.338 ; P=0.041)$. The calculated coefficient of determination $\left(r^{2}\right)$ indicated that, in $11.42 \%$, the linear variation of the growth performance indicator was determined by the degree of polymerization of inulin applied in the diet.

\section{Plasma Trace Minerals}

In the present experiment, the concentrations of trace minerals determined in blood plasma and the erythrocyte indices were in the reference ranges for this animal species reported in available literature [44, 46, 47].

Compared with the control group, the supplementation of the mixtures with inulin modified the plasma iron 


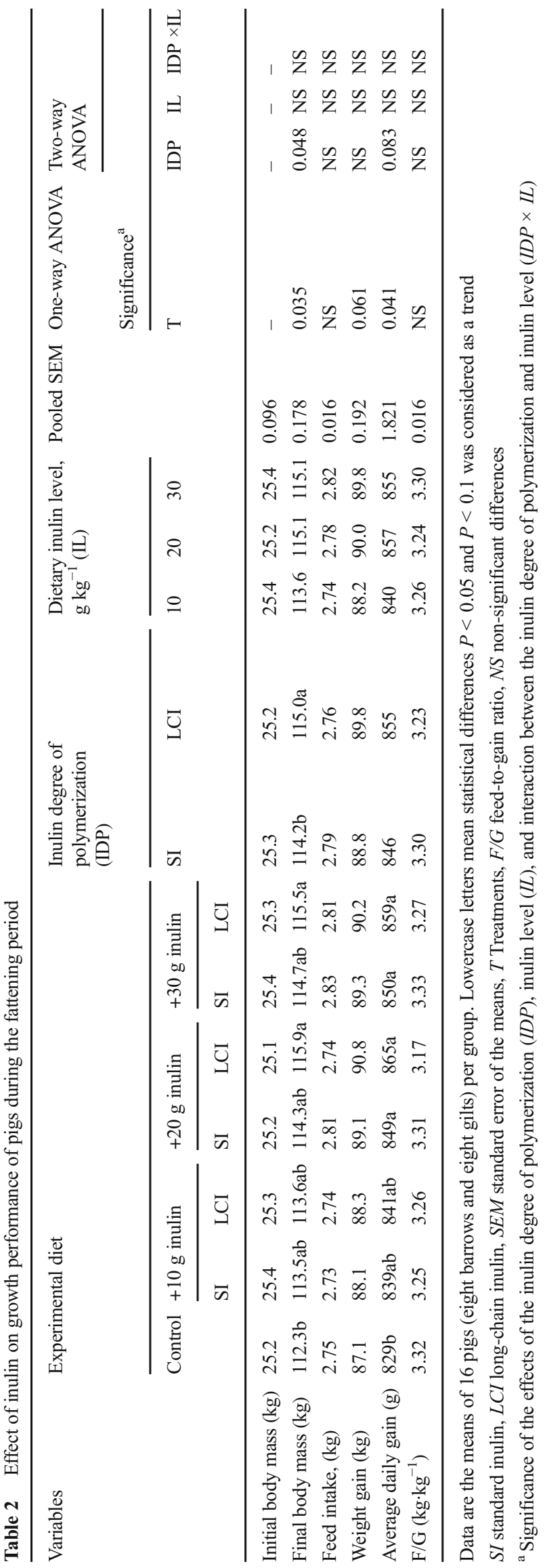

concentration in the fatteners (Table 3). It increased by $30 \%$ in the finishing pigs receiving $20 \mathrm{~g}$ of longchain inulin (one-way ANOVA, $P=0.046$ ). The multivariate analysis also confirmed the tendency toward an effect of LCI on the plasma iron level, which was greater than the impact exerted by inulin with a lower degree of polymerization (two-way ANOVA, $P=0.074$ ). Higher plasma levels of this element, i.e., from 5 to $13 \%$ higher than in the control, were also detected in the other groups, but the differences were not statistically significant. Inulin influenced the plasma copper content only in the first phase of the fattening period (Table 3) (one-way ANOVA, $P=0.044$ ), and this was primarily observed in the case of the LCI supplementation (two-way ANOVA, $P=0.020)$. The greatest changes were noted in the plasma zinc concentration throughout the feeding period (one-way ANOVA, $P<0.05$ ). In comparison with the control group, an elevated level of this element was detected in the inulin-supplemented groups, except for that receiving $\mathrm{LCI}\left(\mathrm{DP}_{\mathrm{av}} \geq 23\right)$ at the doses of 10 and $20 \mathrm{~g} \cdot \mathrm{kg}^{-1}$ of the mixture. Simultaneously, slightly higher iron concentrations were noted in these groups. The analysis of the significance of the linear model variables (IDP; IL) confirmed the effect of the degree of inulin polymerization on the plasma zinc content in the first and second phase as well as the entire fattening period (two-way ANOVA, $P<0.05)$. Additionally, the inulin dose had a significant effect on the concentration of this element in the first phase of the fattening period as well as throughout the fattening period. Furthermore, a combined effect of these two variables on the blood plasma zinc content was observed in the first phase of the fattening period (two-way ANOVA, $P=0.042$ ), and a tendency toward such changes was noted throughout the fattening period (two-way ANOVA, $P=0.077$ ). The calculated Spearman rank correlation coefficient $(R)$ indicated a moderate negative correlation between the inulin polymerization degree and plasma zinc levels $(R=-0.439 ; P=0.002)$. The coefficient of determination $\left(r^{2}\right)$ showed that $19.27 \%$ of the variation in the plasma levels of the element was determined by the degree of inulin polymerization.

\section{Erythrocyte Indices}

The inulin addition to the mixtures did not induce changes in the levels of such erythrocyte indices as the red blood cell (RBC) count and the mean corpuscular volume (MCV) (Table 3). In contrast, the supplementation with this additive altered the hemoglobin content. Compared with the control, the greatest 


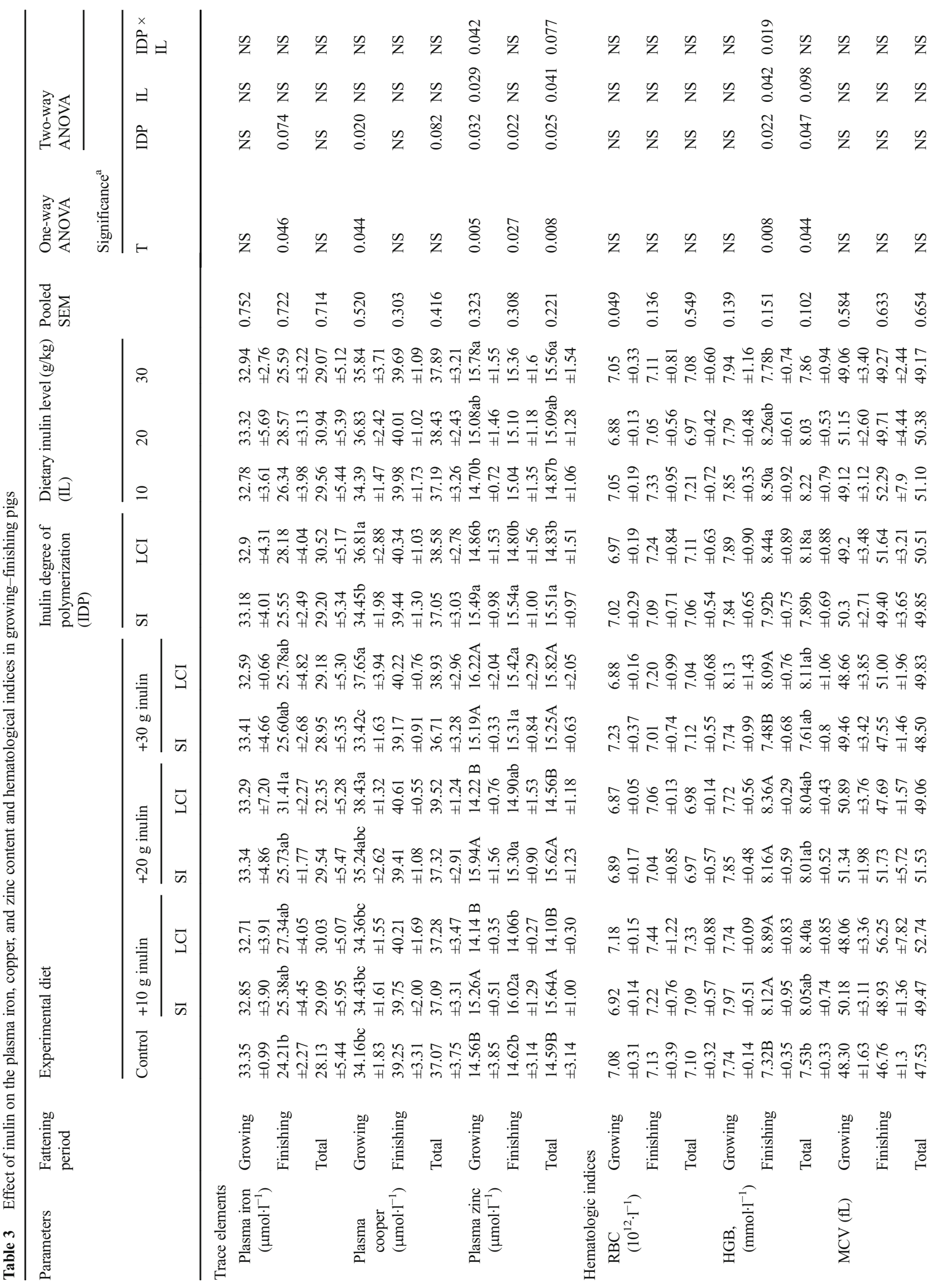




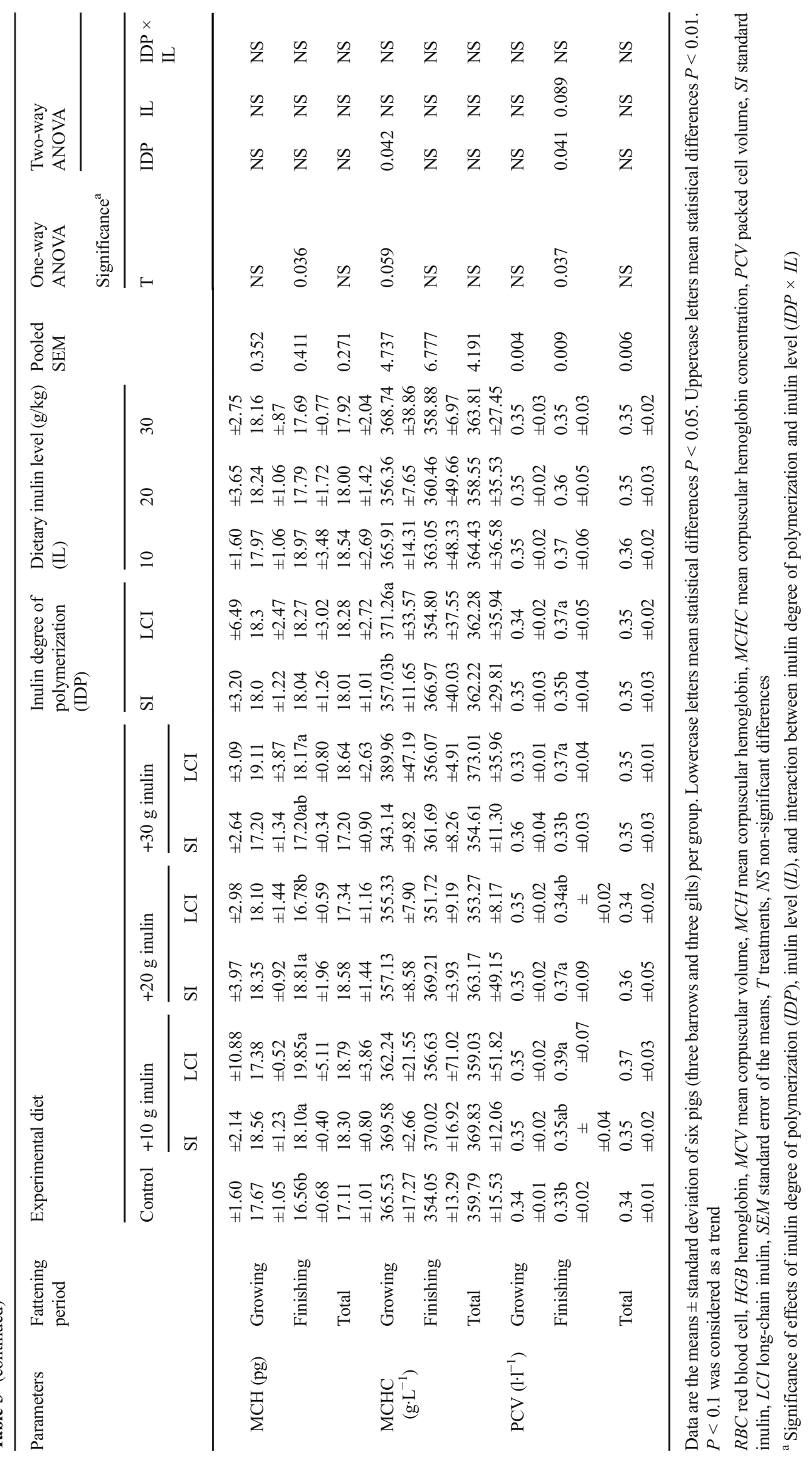


changes were exhibited by the animals in the second phase of the fattening period, when the hemoglobin level increased by $11-21 \%$ (one-way ANOVA, $P=0.008$ ), with the exception of the group supplemented with $30 \mathrm{~g}$ of standard inulin (SI), in which no hemoglobin increase was noted. The multivariate analysis of variance confirmed the impact of both the inulin polymerization degree and its dose as well as the combined effect of these two factors on the analyzed variable (two-way ANOVA, $P<0.05)$. The long-chain inulin increased the hemoglobin level more efficiently (by $11 \%$ ) in comparison with the standard inulin. A reverse correlation between the inulin supplementation and the blood hemoglobin level was also noted. The addition of $10 \mathrm{~g} \cdot \mathrm{kg}^{-1}$ inulin to the mixture increased the hemoglobin content by $11 \%$, relative to the highest inulin dose $\left(30 \mathrm{~g} \cdot \mathrm{kg}^{-1}\right)$. Throughout the fattening period, a similar, although lesser, effect of the inulin addition on the hemoglobin content was noted (one-way ANOVA, $P=0.044)$. The analysis of variance taking into account the polymerization effect confirmed the stronger impact of the long-chain inulin on this blood index (two-way ANOVA, $P=0.047)$. In turn, the effect of the inulin dose was weaker and only a tendency toward increased hemoglobin synthesis at the lower inulin dose added to the mixture was found (twoway ANOVA, $P<0.1$ ). Similarly, the calculated Pearson correlation coefficient $(r)$ between the dose of the inulin addition and the hemoglobin concentration confirmed their low negative correlation $(r=-0.369 ; P=0.010)$. The coefficient of determination $\left(r^{2}\right)$ showed that $13.61 \%$ of the hemoglobin level variation was modified by the added inulin dose.

The mean cell hemoglobin $(\mathrm{MCH})$ index was modified by the inulin supplementation of the mixtures only in the second phase of the fattening period, compared with the control (oneway ANOVA, $P=0.036$ ). In the first phase of the fattening period, a positive effect of the degree of inulin chain polymerization on the mean corpuscular hemoglobin concentration (MCHC) was observed (two-way ANOVA, $P=0.042$ ).

Compared with the control, the packed cell volume (PCV) was significantly higher (one-way ANOVA, $P=0.037$ ) in the blood of animals supplemented with $20 \mathrm{~g}$ of SI or 10 and $30 \mathrm{~g}$ of LCI only in the second phase of the fattening period. In this phase of fattening, there was a positive effect of the degree of inulin chain polymerization on PCV (two-way ANOVA, $P=0.041)$. Simultaneously, a tendency toward a decrease in this hematological index at the increasing inulin doses was observed (two-way ANOVA, $P<0.1$ ).

\section{Discussion}

Supplementation with inulin as a fattener feed additive increased the daily gains and the final body weight $(P<0.05)$. The literature presents many investigations of inulin supplementation in the diet for many animal species. However, the results obtained are often ambiguous in terms of the effects on the growth performance. This may be associated with the diverse types of inulin differing in the polymerization degree or mixtures thereof with oligofructose (Table 4). A beneficial effect of inulin supplementation on the final body weight was reported in investigations conducted on pigs [30], broiler chicken [33], and fish [36]. In the present research, a stronger impact on the final body weight in the fatteners was noted after addition of the long-chain inulin (group LCI; $\mathrm{DP}_{\mathrm{av}} \geq 23$ ), while there were no concurrent changes in the feed intake in the experimental groups. This may suggest improvement of utilization of nutrients from the mixtures supplemented with the long-chain inulin reflected in the final body weight. According to the literature, inulin-induced changes in bacterial populations can exert a beneficial effect on the digestion and absorption processes, including the activity of intestinal enzymes, nutrient metabolism, and intestinal histomorphology, thereby contributing to the growth performance $[12,16,17]$.

The results obtained in this study confirm the significant role of the inulin addition in increasing the zinc, copper, and iron concentration in fatteners' blood plasma $(P<0.05)$. The reported changes were more pronounced in the case of zinc rather than copper and iron, which may have resulted from a better supply of these trace elements in the organism. In the case of iron, the regulation of absorption from the intestinal epithelium into the blood largely depends on the amount of iron stored in the organisms and the erythropoiesis rate. An increasing iron demand at low amounts stored leads to increased absorption of this element [44]. The stimulatory effect of inulin on Fe, $\mathrm{Zn}$, and $\mathrm{Cu}$ absorption and on the plasma levels of these biometals was reported previously [13, 15, 29, 36]. The mechanism of improved availability of macroelements and microelements by fructans is associated with fermentation thereof by the intestinal saprophytic microbiota and formation of organic acids (primarily SCFA), which lower the $\mathrm{pH}$ of the intestinal contents and increase the solubility of mineral compounds [48]. Increased absorption may also result from improved integrity of the intestinal epithelium barrier providing protection against pathogenic bacteria, increased proliferation of epithelial cells, and reduced inflammation in response to SCFA production [12, 17, 48]. Simultaneously, inulin administration is accompanied by increased bacterial hydrolysis of phytates, which contain complexed zinc, iron, and copper [29, 48]. Phytates are present in substantial amounts in grains, cereal bran, and legumes, i.e., the basic feed components of feed mixtures for pigs. Yasuda et al. [19] and Tako et al. [18] reported a positive effect of inulin on the expression of genes encoding Fe transporters, enzymes, and ferritin in intestinal enterocytes and its inhibiting effect on inflammationrelated genes, which exerts a positive influence on iron 


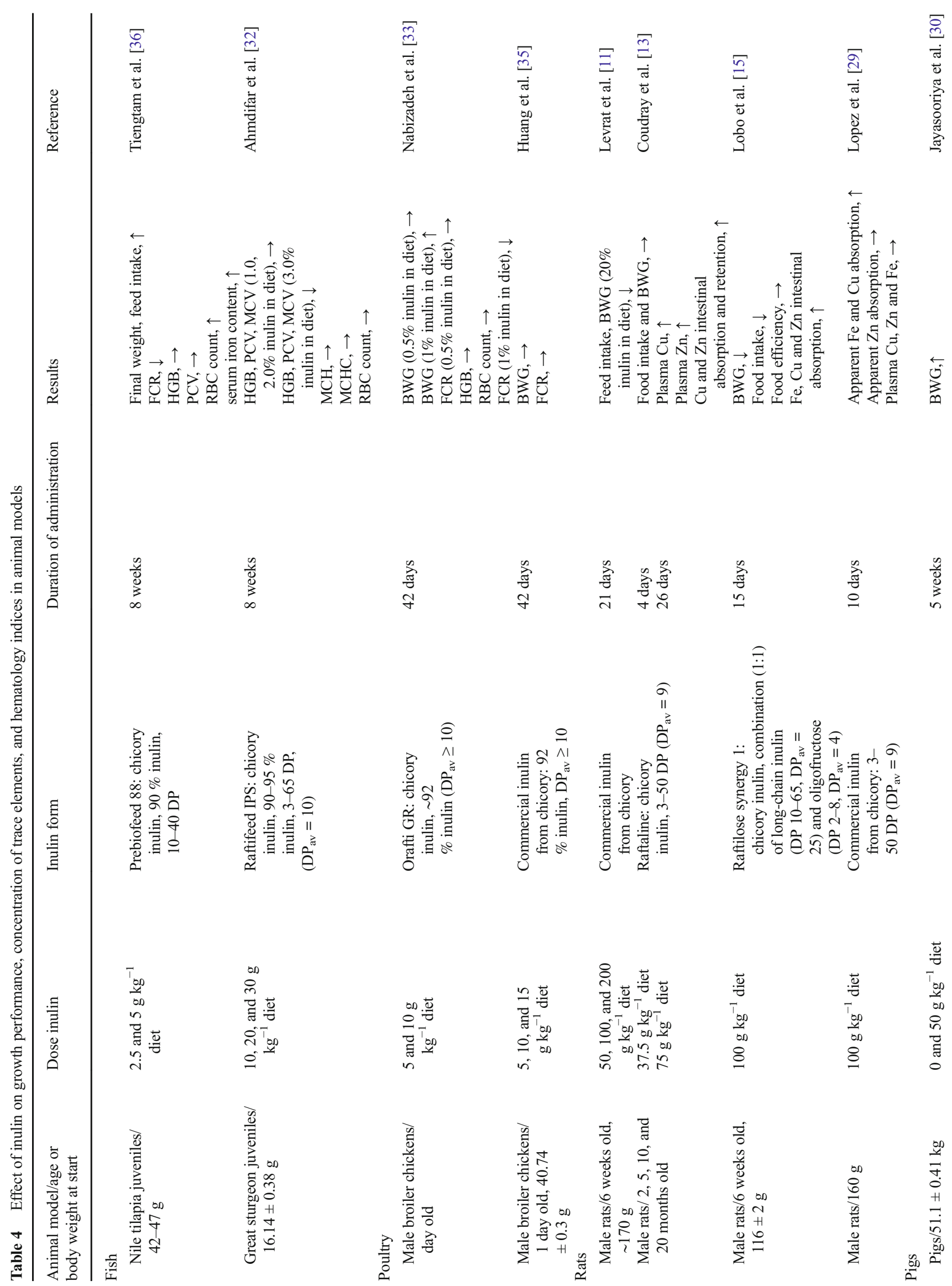




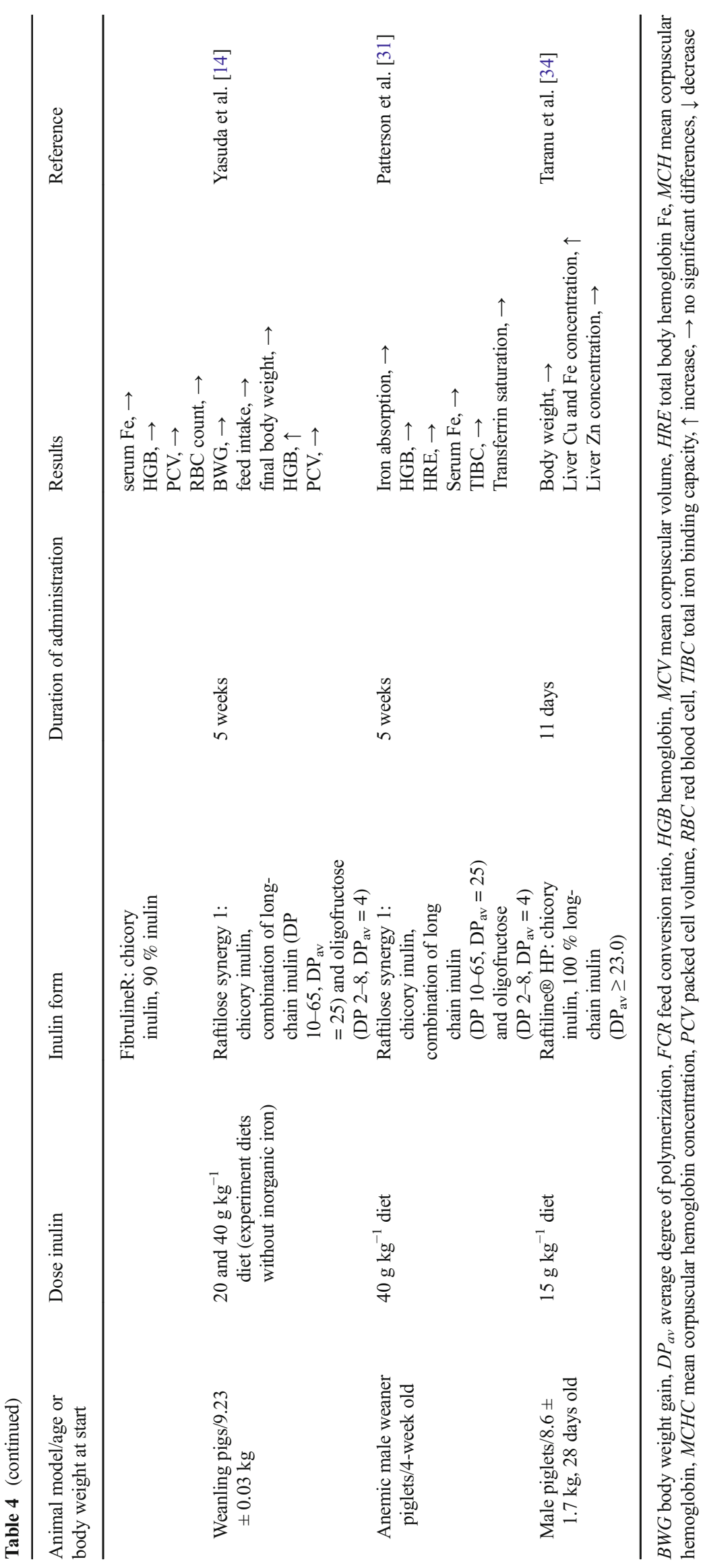


metabolism as well. Yasuda et al. [19] also found that the inulin-induced improvement in iron utilization was independent of the inulin chain polymerization degree.

In the study, there were differences between the effects of the standard inulin and the long-chain inulin on the plasma content of the analyzed trace elements. Other animal investigations focused on assessment of $\mathrm{Fe}, \mathrm{Zn}$, or $\mathrm{Cu}$ absorption revealed either beneficial effects or absence of an impact of these fructans on $\mathrm{Fe}, \mathrm{Zn}$, or $\mathrm{Cu}$ absorption $[13,15,29,31]$ (Table 4). The differences between the results obtained in this study and literature reports may be associated with interspecific differences, animal age, a shorter period of inulin supplementation of the feed, and the degree of inulin polymerization. Alles et al. [49] and van de Wiele et al. [6] indicate that the degree of polymerization (DP) largely determines the site of fructan fermentation in the gastrointestinal tract. Fructans with a low polymerization degree undergo relatively fast microbial fermentation, while long-chain fructans are more resistant to fermentation and undergo the process only in the end parts of the gastrointestinal tract $[6,38,50]$. Kleessen et al. [4] showed that the effect of fructans on the level of short-chain fatty acids produced in the cecum and colon depended on the chain length. In their investigations based on addition of a mixture (1:1) of long-chain inulin $\left(\mathrm{DP}_{\mathrm{av}}=25\right)$ and oligofructose, Yasuda et al. [51] determined mainly inulin decomposition in the jejunum, cecum, and colon in piglets. The process was characterized by the greatest dynamics in the cecum. Alles et al. [49] and Patterson et al. [38] reported that fructans with varied degrees of polymerization stimulated the growth and activity of various Bifidobacterium and Lactobacillus species present in the entire gastrointestinal tract. Short-chain fructans were fermented by a greater number of Bifidobacterium species [52]. This slightly different fermentation site in the gastrointestinal tract, dependent on the polymerization degree, and the influence of inulin on the intestinal microbiota can have varying effects on the absorption of trace elements and their blood concentration. In the present study, throughout the animal fattening period, inulin with the lower polymerization degree (SI; $\left.\mathrm{DP}_{\mathrm{av}} \geq 10\right)$ increased the blood plasma zinc content $(P=0.025)$. In monogastric animals, mineral compounds are mainly absorbed in the small intestine and, to a lesser extent, in the colon [53]. Zinc is absorbed in the duodenum and jejunum, and phytic acid is the basic inhibitor of absorption of this element [54]. These complexes can be hydrolyzed by the intestinal microbiota stimulated by the presence of inulin, which contributes to the release of bound zinc. Given the highly limited zinc absorption in the large intestine, release thereof through fermentation has biological relevance probably only at application of standard short-chain inulin, which is more easily degraded by gastrointestinal bacteria in the upper intestine parts. The results presented in this study also indicate a plasma zinc concentration increasing together with the inulin dose, particularly in the first phase of the fattening period $(P=0.029)$, which implies an interaction between the inulin dose and the polymerization degree $(P=0.042)$. Similarly, Levrat et al. [11] confirmed the linear relationship between the inulin dietary content $(0,5,10$, and $20 \%$ ) and $\mathrm{Ca}$ and $\mathrm{Mg}$ absorption in the rat cecum. On the other hand, increased zinc absorption may result in reduced iron and copper absorption and, consequently, iron metabolism disturbances (reduced concentrations of hemoglobin and hematocrit), which was also noted in the present study.

After the addition of inulin with the longer fructose chain (LCI; $\mathrm{DP}_{\mathrm{av}} \geq 23$ ), a reverse situation was observed, i.e., increased amounts of copper $(P<0.05)$ and iron $(P<0.1)$ in the plasma. This is probably related to the site of long-chain inulin fermentation and absorption of these elements. In contrast to zinc, both iron and copper can partially be absorbed in the large intestine [55-57]. In their observation of enhanced $\mathrm{Cu}$ and $\mathrm{Fe}$ absorption in rats receiving inulin supplementation, Lopez et al. [29] confirmed that it primarily reflected the increased absorption of these microelements in the large intestine.

Assessment of the hemoglobin level is an efficient indicator of the iron content in the organism while monitoring the effects of nutritional intervention. Our results of the evaluation of erythrocyte indices have revealed an increase caused by the inulin addition in both the hemoglobin content and the $\mathrm{MCH}$ and PCV levels, compared with the control $(P<0.05)$, which may be associated with the enhanced absorption of the elements involved in erythropoietic processes (copper, iron, zinc). A similar positive effect of inulin supplementation has also been reported by Yasuda et al. [14] (Table 4). The investigators found a $15 \%$ increase in the hemoglobin concentration in piglets' blood $(P<0.01)$ in inulin-supplemented groups, compared with the control group. A similar impact of inulin addition has been noted in experiments on calves [58]. The authors explained the positive influence of inulin on the red blood cell system by better absorption of iron resulting from optimization of conditions prevailing in the intestine and enhanced utilization of iron in hemoglobin synthesis. Our findings related to the assessment of the hemoglobin content and the PCV and MCHC indices have demonstrated a more beneficial effect of the long-chain inulin addition $(P<0.05)$. These indices are associated with the blood hemoglobin concentration, which is a most common criterion in diagnosis of iron deficiency. In investigations conducted on other animal species, no such effect of inulin on erythrocyte indices was reported [30-33] (Table 4). In the present study, in particular in the second phase of the fattening period, a negative impact of the increasing inulin doses $(r=-0.369$; $P=0.010)$ on the hemoglobin concentration $(P=0.042)$ and the PCV value $(P=0.089)$ was observed. Similar effects were noted by Ahmdifar et al. [32] for inulin supplementation in sturgeon feed. This may have been caused by enhanced zinc absorption at the higher doses of inulin. Zinc induces 
production of metallothionein in enterocytes, and the protein binds copper, thereby preventing absorption thereof, which exerts an effect on iron metabolism and the level of erythrocyte indices [53].

\section{Conclusions}

The inulin supplementation effectively modified the evaluated indices, and $20 \mathrm{~g} \cdot \mathrm{kg}^{-1}$ diet was found to be an optimal dose. A clearly more beneficial effect was exerted by the long-chain inulin. A more pronounced effect of standard inulin on the final body weight, blood copper and iron concentrations, and erythrocyte indices was noted.

The different inulin effects depending on its polymerization degree suggest a necessity to carry out further investigations on the combined application thereof in animal nutrition. For evaluation of the trace minerals status, more sensitive indicators such as molecular biomarkers should additionally be used. This will contribute to detailed assessment of induction of a possible synergistic effect on trace element supply in the organism and relevant red blood cell indices.

Acknowledgments This research was supported in part by the project No. 12006710 from the Polish National Center of Research and Development (NCBiR).

Compliance with ethical standards The study was approved by the Local Ethics Committee on Animal Experimentation of the University of Life Sciences in Lublin, Poland.

Conflicts of interest The authors declare that they have no conflicts of interest.

Open Access This article is distributed under the terms of the Creative Commons Attribution 4.0 International License (http:// creativecommons.org/licenses/by/4.0/), which permits unrestricted use, distribution, and reproduction in any medium, provided you give appropriate credit to the original author(s) and the source, provide a link to the Creative Commons license, and indicate if changes were made.

\section{References}

1. Franck A (2002) Technological functionality of inulin and oligofructose. Br J Nutr 87:287-291. doi:10.1079/BJN/2002550

2. Kelly G (2008) Inulin-type prebiotics - a review: part 1. Altern Med Rev 13:315-329

3. Gibson GR, Beatty ER, Wang X, Cummings JH (1995) Selective stimulation of Bifidobacteria in the human colon by oligofructose and inulin. Gastroenterology 108:975-982. doi:10.1016/00165085(95)90192-2

4. Kleessen B, Hartman L, Balut M (2001) Oligofructose and long-chain inulin: influence on the gut microbial ecology of rats associated with a human faecal flora. Br J Nutr 2:291-300. doi:10.1079/BJN2001403

5. Han KH, Kobayashi Y, Nakamura Y, Shimada KI, Aritsuka T, Ohba K, Morita T, Fukushima M (2014) Comparison of the effects of longer chain inulins with different degrees of polymerization on colonic fermentation in a mixed culture of swine fecal bacteria. $\mathrm{J}$ Nutr Sci Vitaminol 60:206-212. doi:10.3177/jnsv.60.206

6. van de Wiele T, Boon N, Possemiers S, Jacobs H, Verstraete W (2007) Inulin-type fructans of longer degree of polymerization exert more pronounced in vitro prebiotic effects. J Appl Microbiol 102: 452-460

7. Glibowski P (2010) Effect of thermal and mechanical factors on rheological properties of high performance inulin gels and spreads. J Food Eng 99:106-113. doi:10.1111/j.1365-2672.2006.03084.x

8. Tárrega A, Torres J, Costell E (2011) Influence of the chain-length distribution of inulin on the rheology and microstructure of prebiotic dairy desserts. J Food Eng 104:356-363. doi:10.1016/j. jfoodeng.2010.12.028

9. Ronkart SN, Blecker CS, Fourmanoir H, Fougnies C, Deroanne C, Herck JV, Paquot M (2007) Isolation and identification of inulooligosaccharides resulting frominulin hydrolysis. Anal Chim Acta 604:81-87. doi:10.1016/j.aca.2007.07.073

10. Roberfroid MB, Delzenne NM (1998) Dietary fructans. Annu Rev Nutr 18:117-143

11. Levrat MA, Rémésy C, Demigné C (1991) High propionic acid fermentations and mineral accumulation in the cecum of rats adapted to different levels of inulin. J Nutr 121:1730-1737

12. Coudray C, Bellanger J, Castiglia-Delav C, Remesy C, Vermorel M, Rayssignuier Y (1997) Effect of soluble or partly soluble dietary fibres supplementation on absorption and balance of calcium, magnesium, iron and zinc in healthy young men. Eur J Clin Nutr 51: 375-380. doi:10.1038/sj.ejen.1600417

13. Coudray C, Feillet-Coudray C, Gueux E, Mazur A, Rayssiguier Y (2006) Dietary inulin intake and age can affect intestinal absorption of zinc and copper in rats. J Nutr 136:117-122

14. Yasuda K, Roneker KR, Miller DD, Welch RM, Lei GX (2006) Supplemental dietary inulin affects the bioavailability of iron in corn and soybean meal to young pigs. J Nutr 136:3033-3038

15. Lobo AR, Mancini Filho J, Alvares EP, Cocato ML, Colli C (2009) Effects of dietary lipid composition and inulin-type fructans on mineral bioavailability in growing rats. Nutrition 25:216-225. doi:10.1016/j.nut.2008.08.002

16. Petkevicius S, Bach Knudsen KE, Murrell KD (2003) Effects of Oesopha-gostomum dentatum and dietary carbohydrates on morphology of the large intestine of pigs. Vet Parasitol 116:125-138. doi:10.1016/S0304-4017(03)00260-7

17. Yeung CK, Glahn RP, Welch RM, Miller DD (2005) Prebiotics and iron bioavailability - is there a connection? J Food Sci 70:88-92. doi:10.1111/j.1365-2621.2005.tb09984.x

18. Tako E, Glahn RP, Welch RM, Lei X, Yasuda K, Miller DD (2008) Dietary inulin affects the expression of intestinal enterocyte iron transporters, receptors and storage protein and alters the microbiota in the pig intestine. Br J Nutr 99:472-480. doi:10.1017/S0007114507825128

19. Yasuda K, Dawson HD, Wasmuth EV, Roneker C, Chen C, Urban JF, Welch RM, Miller DD, Lei XG (2009) Supplemental dietary inulin influences expression of iron and inflammation related genes in young pigs. J Nutr 139:2018-2023. doi:10.3945/jn.109.110528

20. Studziński T, Matras J, Grela ER, Valverde Piedra JL, Truchliński J, Tatara MR (2006) Minerals: functions, requirements, excessive intake and toxicity. In: Mosenthin R, Zentek J, Żebrowska T (eds) Biology of Nutrition in Growing Animals. Elsevier, Burlington, USA, pp. 467-509

21. Harvey JW (2008) Iron metabolism and its disorders. In: Kaneko JJ, Harvey JW, Bruss ML (eds) Clinical biochemistry of domestic animals, 6th edn. Elsevier, Inc, Burlington, USA, pp. 259-285

22. Huber KL, Cousins RJ (1993) Zinc metabolism and metallothionein expression in bone marrow during erythropoiesis. Am J Phys 264:770-770 
23. Reinstein NH, Lonnerdal B, Keen CL, Hurley LS (1984) Zinccopper interactions in the pregnant rat: fetal outcome and maternal and fetal zinc, copper and iron. J Nutr 114:1266-1279

24. Brewer GJ, Hill GM, Dick RD, Prasad AS, Cossack ZT (1985) Interaction of trace elements: clinical significance. J Am Coll Nutr 4:33-38. doi:10.1080/07315724.1985.10720064

25. Goldhaber SB (2003) Trace element risk assessment: essentiality vs toxicity. Regul Toxicol Pharmacol 38:232-242. doi:10.1016/S0273-2300(02)00020-X

26. Konomi A, Yokoi K (2005) Zinc deficiency decreases plasma erythropoietin concentration in rats. Biol Trace Elem Res 107: 289-292. doi:10.1385/BTER:107:3:289

27. Cotzias GC (1967) Importance of trace substances in environmental health as exemplified by manganese. Trace Sub Environ Health 1: 5-19

28. Reinhold JG (1975) Trace elements: a selective survey. Clin Chem 21:476-500

29. Lopez HW, Coudray C, Levrat-Verny M, Feillet-Coudray C, Demigné C, Rémésy C (2000) Fructooligosaccharides enhance mineral apparent absorption and counteract the deleterious effects of phytic acid on mineral homeostasis in rats. J Nutr Biochem 11: 500-508. doi:10.1016/S0955-2863(00)00109-1

30. Jayasooriya SD, Pluske JR, Dunshea FR, Gill H, Ponnampalam EN (2009) Dietary iron improves iron status in finisher pigs fed wheatbased diets. Manipulating Pig Production XII Proceedings of the Twelfth Biennial Conference of the Australasian Pig Science Association (APSA). Publisher Australasian Pig Science Association. ISBN 978-0-9806880-0-9

31. Patterson JK, Rutzke MA, Fubini SL, Glahn RP, Welch RM, Lei X, Miller DD (2009) Dietary inulin supplementation does not promote colonic iron absorption in a porcine model. J Agric Food Chem 57: 5250-5256. doi:10.1021/jf900698x

32. Ahmdifar E, Akrami R, Ghelichi A, Zarejabad AM (2011) Effects of different dietary prebiotic inulin levels on blood serum enzymes, hematologic, and biochemical parameters of great sturgeon (Huso huso) juveniles. Comp Clin Pathol 20: 447-451. doi:10.1007/s00580-010-1017-2

33. Nabizadeh A, Gevorkyan O, Golian A (2012) Effect of inulin on some hematological, immunological parameters and broiler chickens performance. J Anim Vet Adv 11:3304-3311. doi:10.3923/javaa.2012.3304.3311

34. Taranu I, Marin DE, Untea A, Janczyk P, Motiu M, Criste RD, Souffrant WB (2012) Effect of dietary natural supplements on immune response and mineral bioavailability in piglets after weaning. Czech J Anim Sci 57:332-343

35. Huang Q, Wei Y, Lv Y, Wang Y, Hu T (2015) Effect of dietary inulin supplements on growth performance and intestinal immunological parameters of broiler chickens. Livest Sci 180:172-176. doi:10.1016/j.livsci.2015.07.015

36. Tiengtam N, Khempaka S, Paengkoum P, Boonanuntanasarn S (2015) Effects of inulin and Jerusalem artichoke (Helianthus tuberosus) as prebiotic ingredients in the diet of juvenile Nile tilapia (Oreochromis niloticus). Anim Feed Sci Technol 207:120-129. doi:10.1016/j.anifeedsci.2015.05.008

37. Yasuda K, Roneker KR, Rice S, Welch RM, Miller DD, Lei XG (2008) Effects of three types of inulin on dietary iron bioavailability and site of their disappearance in the digestive tract of young pigs. FASEB J 22(MeetingAbstracts):694.6

38. Patterson JK, Yasuda K, Welch RM, Miller DD, Lei XG (2010) Supplemental dietary inulin of variable chain lengths alters intestinal bacterial populations in young pigs. J Nutr 140:2158-2161. doi:10.3945/jn. 110.130302

39. Grela ER, Sobolewska S, Roziński T (2014) Effect of inulin extracts or inulin-containing plant supplement on blood lipid indices and fatty acid profile in fattener tissues. Pol J Vet Sci 17:93-98. doi:10.2478/pjvs-2014-0012
40. AOAC (2000) Official methods of analysis of AOAC International. 17th edition. Gaithersburg, MD, USA. Association of Analytical Communities. Approved methods of the American Association of Cereal Chemists (AACC)

41. Schram E, Moore S, Bigwood EJ (1954) Chromatographic determination of cysteine as cysteic acid. Biochem J 57:33-37

42. Polish Standard, PN-76/R-64781 (1976) Feed. Determination of phosphorus content. Polish Committee for Standardization, Warsaw, Poland (In Polish)

43. Polish Standard, PN-EN ISO 6869 (2002) Animal feeding stuffs determination of the contents of calcium, copper, iron, magnesium, manganese, potassium, sodium and zinc-method using atomic absorption spectrometry. Polish Committee for Standardization, Warsaw, Poland (In Polish)

44. Reece WO (2015) The composition and functions of blood. In: Reece WO, Erickson HH, Goff JP, Uemura EE (eds) Dukes' physiology of domestic animals, 13th edn. John Wiley \& Sons, Incorporated, Ames, pp. 114-136

45. Statsoft, Inc. (2011). Statistica (data analysis software system), version 10.0 PL. www.statsoft.com.

46. Radostits OM, Gay CC, Blood DC, Hinchcliff KW (2000) Veterinary medicine: a textbook of the diseases of cattle, sheep, pigs, goats and horses, 9th edn. Saunders WB, Philadelphia

47. Weiss DJ, Wardrop KJ (eds) (2010) Schalm's veterinary hematology, Sixth edn. John Wiley \& Sons, Ames, Iowa, USA

48. Scholz-Ahrens KE, Schrezenmeir J (2007) Inulin and oligofructose and mineral metabolism: the evidence from animal trials. J Nutr 137:2513-2523

49. Alles MS, Hautvast JG, Nagengast FM, Hartemink R, Van Laere KM, Jansen JB (1996) Fate of fructo-oligosaccharides in the human intestine. Br J Nutr 76:211-221. doi:10.1079/BJN19960026

50. Roberfroid MB (2007) Inulin-type fructans: functional food ingredients. J Nutr 137:2493-2502. doi:10.1016/j.tifs.2005.08.004

51. Yasuda K, Maiorano R, Welch RM, Miller DD, Lei XG (2007) Cecum is the major degradation site of ingested inulin in young pigs. J Nutr 137:2399-2404

52. Rossi M, Corradini C, Amaretti A, Nicolini M, Pompei A, Zanoni S, Matteuzzi D (2005) Fermentation of fructooligosaccharides and inulin by Bifidobacteria: a comparative study of pure and fecal cultures. Appl Environ Microbiol 71:6150-6158. doi:10.1128/AEM.71.10.6150-6158.2005

53. Goff JP (2015) Minerals. In: Reece WO, Erickson HH, Goff JP, Uemura EE (eds) Dukes' physiology of domestic animals, 13th edn. John Wiley \& Sons, Incorporated, Ames, pp. 567-592

54. O’Dell (1969) Effect of dietary components upon zinc bioavailability. Am J Clin Nutr 22:1315-1322

55. Bowland JP, Braode R, Chamberlain AG, Glascock RF, Mitchell KG (1961) The absorption, distribution and excretion of labelled copper in young pigs given different quantities, as sulphate or sulphide, orally or intravenously. Br J Nutr 15:59-72. doi:10.1079/BJN19610008

56. Bougle D, Vaghefi-Vaezzadeh N, Roland N, Bouvard G, Arhan P, Bureau F, Neuville D, Maubois JL (2002) Influence of short-chain fatty acids on iron absorption by proximal colon. Scand J Gastroenterol 37:1008-1011

57. Blachier F, Vaugelade P, Robert V, Kibangou B, Canonne-Hergaux F, Delpal S, Bureau F, Blottière H, Bougle D (2007) Comparative capacities of the pig colon and duodenum for luminal iron absorption. Can J Physiol Pharmacol 85:185-192. doi:10.1139/Y07-007

58. Masanetz S, Preißinger W, Meyer HHD, Pfaffl MW (2011) Effects of the prebiotics inulin and lactulose on intestinal immunology and hematology of preruminant calves. Animal 5:1099-1106. doi:10.1017/S1751731110002521

59. NRC (2012) Nutrient requirements of swine, Animal Nutrition Series, 11th edn. National Academy Press, USA 